\title{
Endovascular treatment of small cerebral arteriovenous malformations as a primary therapy
}

\author{
Damian Kocur ${ }^{1 A, B, C, D, E, F}$, Nikodem Przybyłko ${ }^{1 A, B, C, D, F}$, Mariusz Hofman ${ }^{1 A, B}$, Tomasz Jamróz ${ }^{1 A, B}$, \\ Aleksandra Ignatowicz ${ }^{1 A, B}$, Jan Baron ${ }^{2 A, B, D}$, Stanisław Kwiek ${ }^{1 A, B, D}$ \\ 'Medical University of Silesia, School of Medicine in Katowice, Department of Neurosurgery, Katowice, Poland \\ 2Medical University of Silesia, School of Medicine in Katowice, Department of Radiology and Nuclear Medicine, Katowice, Poland
}

\section{Abstract}

Purpose: The patient population that would benefit most from endovascular curative treatment of intracranial arteri-
ovenous malformations has not been clearly established. The aim of the study was to determine the effect of curative
embolisation of cerebral arteriovenous malformations with special regard to radiographic and clinical outcomes and
procedure-related complications.

Material and methods: Between January 2009 and December 2014, 18 patients with intracranial arteriovenous malformations were embolised with Onyx with intent to cure. There were four women and 14 men, with a mean age of 40 years (range 10-62 years). Inclusion criteria were: maximal diameter of the lesions $\leq 3 \mathrm{~cm}$ and arterial supply consisting of no more than two major arteries. Five (27.8\%) patients had ruptured lesions, and $13(72.2 \%)$ patients had unruptured lesions. Mean arteriovenous malformation size was $2.3 \mathrm{~cm}$ (range $1.5-2.9 \mathrm{~cm}$ ).

Results: Thirty-three procedures were performed in 18 patients. Total obliteration was achieved in five patients (27.8\%). The most common reason for initial incomplete angiographic occlusion was unfavourable angioarchitectural features of arteriovenous malformations, with the rate of $44.4 \%$. The mean follow-up of patients with complete occlusion was 35.2 months (range 18-60 months). Complication rate was $12.1 \%$. One patient had permanent neurological deficit with resulting morbidity of $5.6 \%$. There were no deaths.

Conclusions: Embolisation of intracranial arteriovenous malformations plays a limited role as a sole therapeutic modality even in terms of small lesions with two or fewer arterial feeders, although larger prospective series are necessary to confirm these findings. Associated complications are not trivial and should be considered when choosing this form of treatment.

Key words: endovascular treatment, cerebral arteriovenous malformations, embolization.

\section{Introduction}

Arteriovenous malformations (AVMs) are heterogeneous and infrequent vascular lesions that may be diagnosed following acute headache and neurological changes associated with intracerebral haemorrhage as well as seizures, focal neurologic deficits, or headache elicited by unruptured malformations [1-3]. It is reported that an increasing number of AVMs are detected incidentally $[1,3]$. They all carry a risk of rupture resulting in significant morbidity and mortality [2]. When deciding to treat an AVM the therapeutic strategy includes surgical resection, radiosurgery, or endovascular technique - alone or in combina-

\section{Correspondence address:}

Damian Kocur, Department of Neurosurgery, 14 Medyków St., 40-752 Katowice, Poland, phone: +48507230 509, fax: +4832 7894501 ,

e-mail:damkocur@gmail.com

Authors' contribution:

A Study design · B Data collection · C Statistical analysis · D Data interpretation · E Manuscript preparation · F Literature search · G Funds collection 
tions [3-5]. As the two former are the mainstay of AVM treatment [6], the indications for the latter can be divided into embolisation before surgical excision in large or giant cortical AVMs, preradiosurgical management with the goal of reducing nidus size, and palliative therapy used to decrease high flow in large non-surgical and nonradiosurgical AVMs with the intention of preserving or improving neurological function $[1,3]$. Nonetheless, in selected cases, AVMs may be angiographically cured with the endovascular approach performed as a "primary therapy" [2,6-10]. To date, the patient population that would benefit most from this form of treatment is not clearly established due to considerable divergences between accessible publications [6]. The aim of the current study is to report our experience with the curative endovascular treatment of brain AVMs with special regard to radiographic and clinical outcomes and procedure-related complications.

\section{Material and methods}

\section{Patients and arteriovenous malformations}

Between January 2009 and December 2014 forty-two patients with AVMs were treated in 90 embolisation sessions at our institution. The group of 18 (42.9\%) patients who were subjected to the treatment with intention to cure constitutes the patient cohort assessed in this report. Inclusion criteria were: maximal diameter of AVMs less than $3 \mathrm{~cm}$ and AVMs arterial supply consisting of no more than two major cerebral or cerebellar arteries. Arteriovenous fistulas as well as aneurysms accompanying AVMs were excluded from this study. For this retrospective study Ethics Committee approval as well as informed patient consent were waived. There were four $(22.2 \%)$ females and $14(77.8 \%)$ males with the age from 10 to 62 years (mean 40 years, SD 14). Clinical presentation was intracranial haemorrhage in five $(27.8 \%)$ out of 18 patients, neurological deficits in five $(27.8 \%)$ out of 18 patients, headaches in three (16.7\%) out of 18 patients, and seizures in two (11\%) patients. AVMs were incidentally diagnosed in three (16.7\%) out of 18 patients. Among the five patients who presented with ruptured AVMs endovascular treatment procedures were performed within 1 to 27 (mean 8.6) days after the onset of symptoms. AVMs locations were: parieto-occipital region in seven $(38.9 \%)$ patients, frontal lobe in four (22.2\%) patients, cerebellar hemisphere in three $(16.7 \%)$ patients, basal ganglia and thalamus in two $(11.1 \%)$ patients, temporal lobe in one $(5.5 \%)$ patient, and perirolandic area in another one $(5.5 \%)$. The size of the AVMs ranged from $1.5 \mathrm{~cm}$ to $2.9 \mathrm{~cm}$ (mean $2.3 \mathrm{~cm} \mathrm{SD}$ $0.4)$. The lesions were fed by one major cerebral or cerebellar artery in 10 (55.5\%) out of 18 patients, and by two major cerebral or cerebellar arteries in the eight (44.5\%) remaining ones. Based on the Spetzler-Martin score there were eight $(44.5 \%)$ grade I AVMs, nine $(50 \%)$ grade II AVMs, and one (5.5\%) grade III AVM.

\section{Embolisation technique}

Digital subtraction angiographies (DSA) performed on Philips Integris Allura 15C were obtained to evaluate accurately the location of the nidus and the exact anatomy of the feeding arteries and draining veins. Endovascular embolisation was the first-line treatment method of all AVMs presented in the current study. All the procedures were done by experienced interventional radiologists, and always after neurosurgical consultations. The patients were treated under general anaesthesia. After superselective transfemoral catheterisation of the AVM feeding pedicle, injection of the Onyx (ev3, Irvine, CA) was carried out with the intention of reaching the nidus of the AVM only, without occluding the arterial feeders or the draining veins. The flow-directed microcatheter Ultraflow (ev3) was always used. In cases of AVMs supplied by two or more arterial pedicles staged embolisation was performed as a rule. During the procedures heparinised saline was continuously infused into the arterial line. After embolisation, every patient was transferred to the intensive care unit for observation. Patients with unruptured AVMs after uncomplicated treatment were typically discharged from hospital on postoperative day 3 . The remaining patients were discharged from hospital after clinical stabilisation.

\section{Clinical and angiographic evaluation}

A control angiogram was always obtained immediately after the embolization and at minimum follow-up of 4 weeks. The lack of contrast filling within the AVM nidus was classified as a complete occlusion. Patients with incompletely occluded AVMs were offered radiosurgical or surgical therapy. Recanalisation was defined as any increase in nidal filling at follow-up. In cases of revascularisation following initial complete occlusion of AVMs, the patients were retreated via endovascular approach or were referred to stereotactic radiotherapy and the decisions were made arbitrarily choosing the optimal strategy for an individual patient. Each time clinical evaluation was recorded on admission to hospital, directly after endovascular procedure, at discharge from hospital, and during the last angiographic follow-up period.

\section{Results}

\section{Angiographic results}

In the 18 patients analysed in the study 33 endovascular treatment sessions were performed. The initial complete AVM occlusion was achieved in eight cases (44.4\%) and it was obtained in 16 procedures. The primary incomplete occlusion of the remaining 10 AVMs resulted from difficulties of accessing a nidus through arterial feeding arteries in eight patients (44.4\%) and occurrence of complication 
Table 1. Summary of patients with arteriovenous malformations treated via endovascular approach with intent to cure

\begin{tabular}{|c|c|c|c|c|c|c|c|c|c|c|c|}
\hline \multicolumn{3}{|c|}{ Patients } & \multicolumn{4}{|c|}{ AVMs } & \multicolumn{5}{|c|}{ Angiographic outcome } \\
\hline No & Age/Sex & $\begin{array}{c}\text { Clinical } \\
\text { presentation }\end{array}$ & Location & $\begin{array}{l}\text { Arterial } \\
\text { feeders }\end{array}$ & $\begin{array}{l}\text { Size } \\
(\mathrm{cm})\end{array}$ & S-M & $\begin{array}{c}\text { Initial } \\
\text { occlusion }\end{array}$ & $\begin{array}{l}\text { No of } \\
\text { sessions }\end{array}$ & $\begin{array}{c}\text { Technical } \\
\text { adverse } \\
\text { events }\end{array}$ & $\begin{array}{c}\text { Follow-up } \\
\text { period }\end{array}$ & $\begin{array}{l}\text { Occlusion } \\
\text { at last } \\
\text { follow-up }\end{array}$ \\
\hline 1 & $10 / M$ & $\mathrm{ICH}$ & Parieto-occipital & PCA & 2.1 & 2 & Incomplete & 2 & & 8 & Incomplete \\
\hline 2 & $24 / F$ & Hemiparesis & Thalamus & PCA & 2.6 & 3 & Incomplete & 2 & $\mathrm{ICH}$ & 1 & Incomplete \\
\hline 3 & $23 / M$ & Epilepsy & Parieto-occipital & MCA & 2.7 & 2 & Incomplete & 2 & & 3 & Incomplete \\
\hline 4 & $24 / \mathrm{F}$ & $\mathrm{ICH}$ & Frontal & $\mathrm{ACA}$ & 1.5 & 1 & Complete & 3 & & 24 & Complete \\
\hline 5 & $31 / \mathrm{F}$ & Headache & Basal ganglia & $\mathrm{ACA}$ & 2 & 2 & Complete & 1 & & \multicolumn{2}{|c|}{$\mathrm{N} / \mathrm{a}$ due to lack of consent } \\
\hline 6 & $34 / M$ & Headache & Parieto-occipital & $A C A, P C A$ & 2.6 & 2 & Incomplete & 1 & & \multicolumn{2}{|c|}{$\mathrm{N} / \mathrm{a}$ due to lack of consent } \\
\hline 7 & $43 / \mathrm{M}$ & $\mathrm{ICH}$ & Frontal & $\mathrm{ACA}$ & 1.5 & 1 & Complete & 1 & & 3 & Incomplete \\
\hline 8 & $32 / \mathrm{M}$ & Incidental & Parieto-occipital & MCA, PCA & 2.2 & 2 & Complete & 2 & & \multicolumn{2}{|c|}{$\mathrm{N} / \mathrm{a}$ due to lack of consent } \\
\hline 9 & $43 / F$ & $\mathrm{ICH}$ & $\begin{array}{c}\text { Cerebellar } \\
\text { hemisphere }\end{array}$ & $\begin{array}{l}\text { PICA, } \\
\text { AICA }\end{array}$ & 2.6 & 1 & Incomplete & 2 & & 1 & Incomplete \\
\hline 10 & $44 / M$ & $\begin{array}{l}\text { Cerebellar } \\
\text { syndrome }\end{array}$ & $\begin{array}{c}\text { Cerebellar } \\
\text { hemisphere }\end{array}$ & SCA & 2.8 & 1 & Incomplete & 1 & $\begin{array}{l}\text { Material } \\
\text { reflux }\end{array}$ & 60 & Complete \\
\hline 11 & $46 / \mathrm{M}$ & Headache & Parieto-occipital & $A C A, P C A$ & 2.4 & 1 & Complete & 3 & & 50 & Complete \\
\hline 12 & $49 / M$ & Epilepsy & Frontal & $\mathrm{ACA}$ & 1.7 & 1 & Complete & 2 & $\begin{array}{l}\text { Catheter } \\
\text { gluing }\end{array}$ & 6 & Incomplete \\
\hline 13 & $48 / M$ & $\begin{array}{l}\text { Cerebellar } \\
\text { syndrome }\end{array}$ & $\begin{array}{c}\text { Cerebellar } \\
\text { hemisphere }\end{array}$ & $\begin{array}{l}\text { PICA, } \\
\text { AICA }\end{array}$ & 2 & 1 & Incomplete & 2 & & 3 & Incomplete \\
\hline 14 & $51 / M$ & $\begin{array}{l}\text { Cerebellar } \\
\text { syndrome }\end{array}$ & Parieto-occipital & PCA & 2.2 & 2 & Complete & 3 & $\begin{array}{l}\text { Catheter } \\
\text { gluing }\end{array}$ & 3 & Incomplete \\
\hline 15 & $53 / \mathrm{M}$ & Incidental & Perirolandic & MCA & 2,9 & 2 & Incomplete & 1 & & 24 & Complete \\
\hline 16 & $57 / M$ & $\begin{array}{c}\text { Visual } \\
\text { disturbance }\end{array}$ & Parieto-occipital & MCA, PCA & 2 & 2 & Incomplete & 1 & & 1 & Incomplete \\
\hline 17 & $59 / \mathrm{M}$ & Incidental & Temporal & MCA, PCA & 2.5 & 2 & Incomplete & 3 & & 2 & Incomplete \\
\hline 18 & $62 / M$ & $\mathrm{ICH}$ & Frontal & $M C A, A C A$ & 2.4 & 1 & Complete & 1 & & 18 & Complete \\
\hline
\end{tabular}

ACA - anterior cerebral artery, AICA - anterior inferior cerebellar artery, AVMs - arteriovenous malformations, ICH - intracerebral haemorrhage, MCA - middle cerebral artery, PCA - posterior cerebral artery, PICA - posterior inferior cerebellar artery, SCA - superior cerebellar artery, S-M - Spetzler-Martin grade

in another one (5.6\%). One patient (5.6\%) refused further treatment.

Angiographic follow-up was achieved in 15 (83.3\%) patients and ranged from 1 to 60 months with a mean of 13.8 months (SD 18.6). In 10 (66.7\%) of 15 cases no change in the degree of occlusion at initial angiographic follow-up was observed. Recanalisation occurred in three (20\%) patients. Of these, two patients were retreated by Onyx embolisation therapy without any procedure-related complications. In two (13.3\%) of the 15 followed patients, progressive occlusion was revealed. Complete occlusion of AVMs documented in control angiograms were achieved in five $(33.3 \%)$ out of the 15 followed patients. Detailed data are presented in Table 1.

\section{Clinical outcomes}

Three (16.7\%) patients out of 18 presented new focal neurological deficits in the immediate postprocedural period.
The deficits were temporary in two cases $(11.1 \%)$ and permanent in one (5.6\%). The both former patients presented with transient mild one-sided limb weakness, and in one case it was associated with intraoperative internal carotid artery (ICA) stenosis. The endovascular procedure of the second patient with hemiparesis and AVM in basal ganglia was without complications. Instant post-embolisation control angiographies and computed tomography images were within normal limits, similarly to another patient who complained of progressive two-sided hearing deterioration following consecutive stages of cerebellar hemisphere AVM embolisations via bilateral posterior communicating arteries.

\section{Complications}

There were four (12.1\%) adverse events out of 33 embolisation sessions. In two cases the microcatheters were unintentionally glued to the vessels and broke during the 
removal attempt. The attached parts of the catheters were left in vertebral and internal carotid arteries, respectively, resulting in partial occlusion of the latter vessel with subsequent transient mild hemiparesis. A clinically silent reflux of embolic material into posterior inferior cerebellar artery resulting in partial occlusion of this vessel was noted in a patient with cerebellar AVM. Immediately, $20 \mathrm{mg}$ of abciximab was injected locally with good angiographic effect. As a consequence of intraprocedural AVM perforation, another patient experienced an asymptomatic minor intracerebral haemorrhage in the thalamus, which was treated conservatively. There was one case of rebleeding five months after previous intracerebral haemorrhage in the occipital lobe and initial partial AVM embolisation. The patient was treated conservatively with good outcome, and then he was referred to complementary stereotactic radiosurgery.

\section{Discussion}

Endovascular treatment of patients with cerebral AVMs remains controversial and as a monotherapy plays a limited role in managing these lesions with intent to cure $[6,11]$, which is confirmed by the results of our study. Previous series have shown that the subgroup of patients that may benefit most from this form of therapy is based on morphological characteristics including small size, few supplying pedicles, and accessibility of the nidus $[3,6$, $10,12]$. However, the radiological factors associated with endovascular complete AVM obliteration vary from study to study, and hitherto no consensus has been established with regard to the criteria for curative embolisation [6]. It is also worth mentioning that subtotal occlusion of AVMs achieved by some authors may not be considered therapeutic because it is widely known that it does not confer protection from haemorrhage $[3,9,11]$. What is more, there is published evidence that incompletely obliterated AVMs may be associated with increased risk of bleeding [1]. Thus, only total occlusion of the nidus and the arteriovenous shunt constitutes a definitive cure for AVMs [13].

In the literature, the rate of complete obliteration of AVMs with the use of embolisation as one and only therapeutic modality is up to $53.9 \%$, depending on the patient selection, goals of treatment, and operative techniques $[2,10,13]$. The rate of total occlusion achieved by surgical resection and stereotactic radiotherapy is reported to be $57.1-100 \%$ and $80 \%$, respectively, although it should be noted that each of the two methods has its own indications and limitations [3]. Also, the AVMs that are most responsive to curative endovascular therapy overlap with those most amenable to surgical excision or radiosurgical ablation $[2,6,10]$. Nonetheless, in certain situations an endovascular approach could be undertaken. According to Potts et al., patients with contraindications to surgery, those in whom the haemorrhagic risk of radiosurgical latency period is too high, or those whose personal preference is embolisation are potential candidates for this form of treatment [6]. In order to achieve a satisfactory outcome from the use of embolisation the appropriate patient selection is crucial. Among the anatomical factors influencing the feasibility of curative AVM embolisation the accessibility of the nidus seems to be essential in terms of satisfactory initial obliteration.

In the current study the main reason for incomplete angiographic occlusion during endovascular procedures was unfavourable angioarchitectural features of AVMs with the rate of $44.4 \%$. Meanwhile, according to literature review by Potts et al., the immediate angiographic cure rates vary very widely from $5 \%$ to $94 \%$ [6]. Because all our procedures were performed via direct dominant arterial feeders, the next stage of embolization could not be continued if a nidus remnant was not reachable through this route (Figure 1D).

In the literature there are data reporting that the presence of feeding arterial perforators, choroidal supply, "en passage" arterial feeders, and leptomeningeal collateral supply are associated with a lower cure rate [14]. Thus, to achieve better results the technical feasibility of total endovascular obliteration should be assessed as best as possible on preoperative superselective angiograms $[10,15]$. If an AVM remnant cannot be further treated via transarterial embolisation, a transvenous route may be the option, and the preliminary results are encouraging [6].

Another issue related to endovascular therapy is revascularisation that correlates strictly with the applied embolic agent [6]. Little is known about this phenomenon in reference to AVMs, but it has been reported that it may even affect small lesions [2]. One of the reasons for AVM recurrence is proximal occlusion of the feeding artery without the appropriate penetration of embolic material into the nidus, which results in the development of collateral circulation, although secondary angiogenesis is also probable $[8,13]$. Taking the above into consideration, long-term angiographic follow-up after AVM embolisation is mandatory. It should be mentioned, however, that the optimal timing of angiography performed in order to exclude the AVM recanalisation has not yet beendetermined [10].

In the event of incompletely obliterated AVMs, progressive spontaneous thrombosis may occur, as was observed in two patients in the present study (Figure 1). This rare phenomenon is most likely to be associated with smaller AVM size, a single draining vein, and haemorrhage presentation, and hitherto it has been reported in untreated lesions, after partial surgical resection, as well as following subtotal embolisation of AVMs with isobutyl 2-cyanoacrylate [8,16-18].

Nevertheless, a residual AVM after surgery still has the ability to bleed or rebleed, so the rationale for the "wait-and-see" approach in subsets of AVM remnants after endovascular embolisation is rather unjustified [19]. 

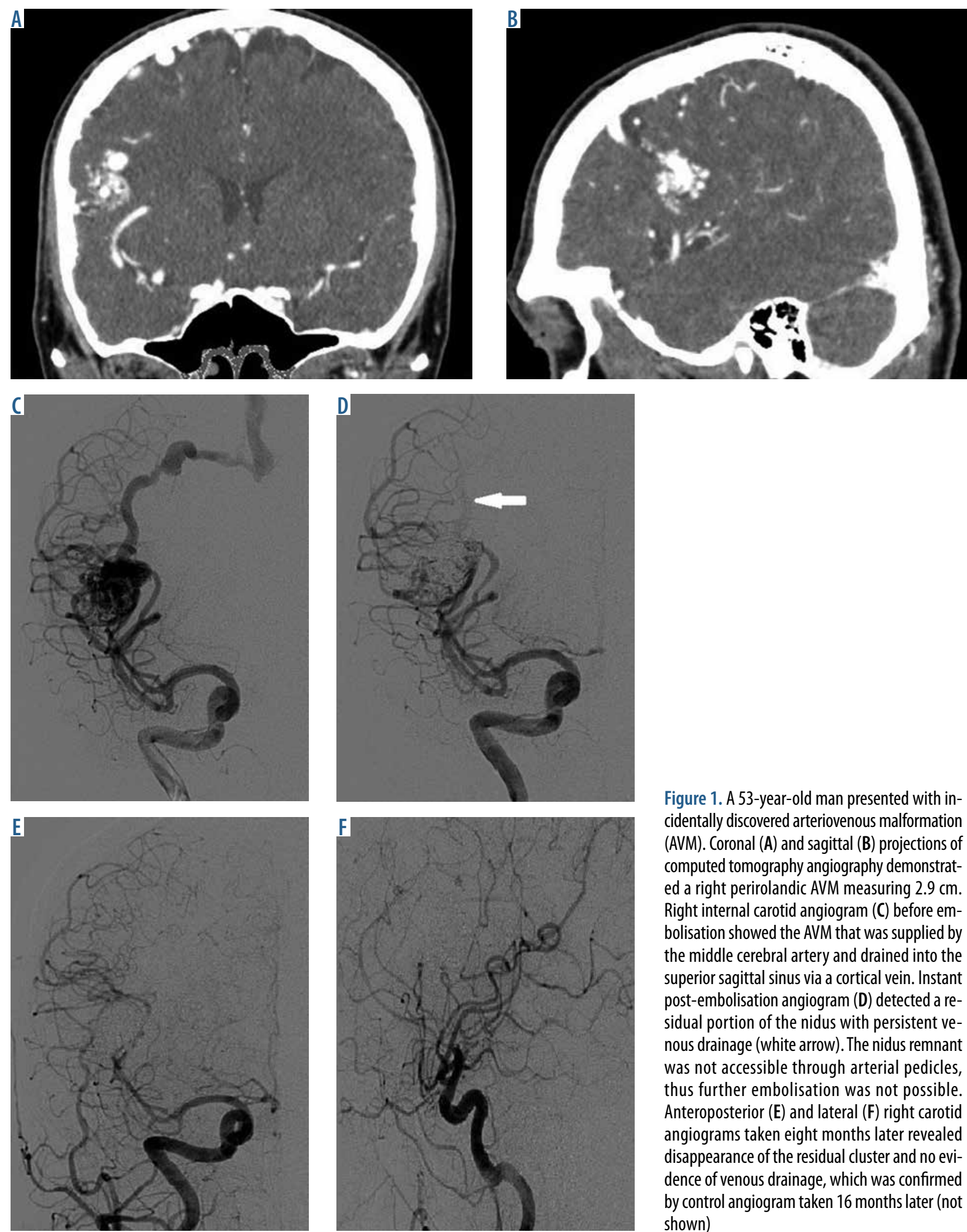

Figure 1. A 53-year-old man presented with incidentally discovered arteriovenous malformation (AVM). Coronal (A) and sagittal (B) projections of computed tomography angiography demonstrated a right perirolandic AVM measuring $2.9 \mathrm{~cm}$. Right internal carotid angiogram (C) before embolisation showed the AVM that was supplied by the middle cerebral artery and drained into the superior sagittal sinus via a cortical vein. Instant post-embolisation angiogram (D) detected a residual portion of the nidus with persistent venous drainage (white arrow). The nidus remnant was not accessible through arterial pedicles, thus further embolisation was not possible. Anteroposterior (E) and lateral (F) right carotid angiograms taken eight months later revealed disappearance of the residual cluster and no evidence of venous drainage, which was confirmed by control angiogram taken 16 months later (not shown)

Moreover, even in terms of progressive thrombosis, recanalisation may appear, so repeated control angiography should not be avoided [16,17]. In the case of incomplete angiographic occlusion of AVMs the most common complementary treatment is reported to be radiosurgery [13].
Nowadays, to occlude AVMs in the mechanism of thrombosis the non-adhesive liquid embolic agent ethylene vinyl alcohol copolymer dissolved in dimethyl sulfoxide, known as Onyx (ev3 Neurovascular, Irvine, CA), is commonly used during embolisation [6,9]. The physical characteristics of Onyx compared with previous n-butyl- 

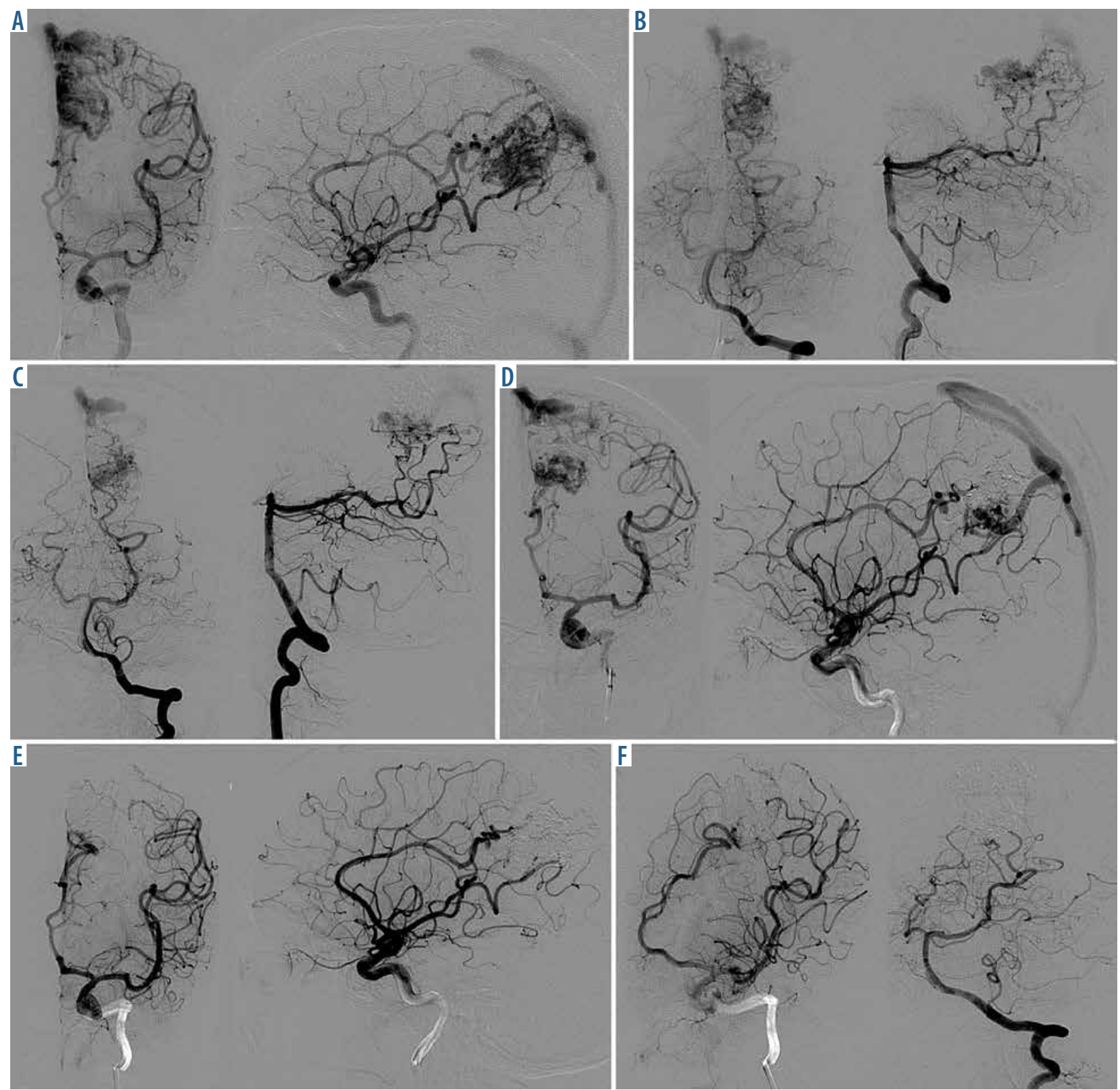

Figure 2. A 47-year-old man presented with increasing headaches. Anteroposterior and lateral left carotid angiograms (A) as well as anteroposterior and lateral left vertebral angiograms (B) demonstrated a left medial parieto-occipital arteriovenous malformation (AVM). The first session of embolisation was performed through the posterior cerebral artery $(C)$ and the second and third ones through the anterior cerebral artery (D). Total occlusion of the AVM was achieved (E). The internal carotid and vertebral angiograms taken 50 months after endovascular treatment revealed no recanalisation, which is presented in oblique projections (F)

cyanoacrylate glue allow more prolonged and controlled injections, which has a positive impact on penetration into the nidus $[6,9,11,20]$. This property, however, predisposes to improper reflux of Onyx, which may result in inadvertent occlusion of normal arterial branches or catheter entrapment $[9,11]$. It is important to know that the presence of branches arising from a specific arterial pedicle and supplying normal brain tissue limits AVM embolisation via this pedicle due to risk thrombosis [9]. In both cases of catheter gluing described in our series, we attempted to remove them by applying traction, which resulted in breakage of the catheters. Although the patients did not present any serious clinical consequenc- es and the follow-up angiograms were within normal limits, studies suggest leaving the trapped catheter in place and cutting it off at the groin sheath, because excessive attempts to withdraw it may induce haemorrhage $[9,11]$. Leaving a catheter extending down the descending aorta is reasonably safe and delayed complications are sporadic [21]. A microcatheter broken above the level of the aortic arch poses a risk of becoming an embolus to the intracranial circulation, so it should be pulled with the use of a microsnare or secured with a self-expanding stent [21]. Surgical removal of the glued catheter may result in severe brain infarction, so it is rational only in selected cases $[10,21]$. As far as conservative treatment is con- 
cerned, it should be noted that the need to put a patient with a retained catheter in the body under anticoagulation has not yet been unequivocally established [10,11].

One of the most important complications of AVM endovascular therapy is haemorrhage, which can be intraoperative and postoperative and may be caused by several factors [21]; AVM bleeding associated with vein stenosis or occlusion and subsequent active arterial supply to the lesion without adequate venous outflow is one of them [9]. The intracerebral haematoma may sometimes require surgical intervention and the clinical sequelae can be fatal $[9,22]$. The haematoma as well as brain oedema may also result from the so-called normal perfusion pressure breakthrough syndrome (NPPBS) in which increased blood flow towards the normal brain vessels after AVM embolisation is observed [6,9,21]. To lower the risk of this negative phenomenon, staged embolisation of AVMs is considered, in order to ensure the recovery of the brain between procedures, especially in the case of large AVMs [9,23]. In 18 patients demonstrated in this study we performed 33 embolisation sessions, and none of the patients developed symptoms of NPPBS (Figure 2). Nonetheless, one patient of our cohort experienced intracerebral bleeding five months after the first stage of AVM embolisation. In the literature, the usefulness of staged embolisation is still debatable, and although it is supposed to lower periprocedural haemorrhagic complications, leaving a residual shunt after the procedure always harbours a certain risk of subsequent AVM bleeding, especially when the venous outlet is occluded $[13,21]$. Taking the above into account, in our opinion the need of multiple embolisation sessions is a serious limitation of endovascular treatment of AVMs as a monotherapy. Because prolonged time of treatment may be associated with persisting risk of intracerebral haemorrhage, the patient selection for embolisation as a sole therapeutic tool for AVM treatment should be highly weighted.

In conclusion, this study found that endovascular management of brain AVMs as a sole therapeutic modality plays a limited role even in terms of small $(<3 \mathrm{~cm})$ lesions with a maximum of two arterial feeders, and it should be applied only in exceptional cases, although larger prospective series are necessary to confirm these findings. Although Onyx embolisation has the potential to be relatively safe, periprocedural complications should not be neglected when selecting this form of treatment.

\section{Conflict of interest}

The authors declare no conflict of interest.

\section{References}

1. Cohen-Gadol A, Conger A, Kulwin C, et al. Endovascular and microsurgical treatment of cerebral arteriovenous malformations: Current recommendations. Surg Neurol Int 2015; 6: 39.

2. Bruno CA, Meyers PM. Endovascular Management of Arteriovenous Malformations of the Brain. Interv Neurol 2013; 1: 109-123.

3. Ogilvy CS, Stieg PE, Awad I, et al. AHA Scientific Statement: Recommendations for the management of intracranial arteriovenous malformations: a statement for healthcare professionals from a special writing group of the Stroke Council, American Stroke Association. Stroke 2001; 32: 1458-1471.

4. van Rooij WJ, Sluzewski M, Beute GN. Brain AVM embolization with Onyx. AJNR Am J Neuroradiol 2007; 28: 172-177; discussion 178.

5. Guo WY, Wikholm G, Karlsson B, et al. Combined embolization and gamma knife radiosurgery for cerebral arteriovenous malformations. Acta Radiol 1993; 34: 600-606.

6. Potts MB, Zumofen DW, Raz E, et al. Curing arteriovenous malfor mations using embolization. Neurosurg Focus 2014; 37: E19.

7. Debrun G, Vinuela F, Fox A, et al. Embolization of cerebral arteriovenous malformations with bucrylate. J Neurosurg 1982; 56: 615-627.

8. Fournier D, TerBrugge KG, Willinsky R et al. Endovascular treatment of intracerebral arteriovenous malformations: experience in 49 cases. J Neurosurg 1991; 75: 228-233.

9. Katsaridis V, Papagiannaki C, Aimar E. Curative embolization of cerebral arteriovenous malformations (AVMs) with Onyx in 101 patients. Neuroradiology 2008; 50: 589-597.
10. Yu SCH, Chan MSY, Lam JMK, et al. Complete obliteration of intracranial arteriovenous malformation with endovascular cyanoacrylate embolization: initial success and rate of permanent cure. AJNR Am J Neuroradiol 2004; 25: 1139-1143.

11. $\mathrm{Xu}$ F, Ni W, Liao Y, et al. Onyx embolization for the treatment of brain arteriovenous malformations. Acta Neurochir (Wien) 2011; 153: 869-878.

12. Sahlein DH, Mora P, Becske T, et al. Nidal embolization of brain arteriovenous malformations: rates of cure, partial embolization, and clinical outcome. J Neurosurg 2012; 117: 65-77.

13. Pierot L, Cognard C, Herbreteau D, et al. Endovascular treatment of brain arteriovenous malformations using a liquid embolic agent: results of a prospective, multicentre study (BRAVO). Eur Radiol 2013; 23: 2838-2845.

14. Willinsky R, Goyal M, Terbrugge K, et al. Embolisation of Small $(<3 \mathrm{~cm})$ Brain Arteriovenous Malformations. Correlation of Angiographic Results to a Proposed Angioarchitecture Grading System. Interv Neuroradiol J Peritherapeutic Neuroradiol Surg Proced Relat Neurosci 2001; 7: 19-27.

15. Valavanis A, Christoforidis G. Endovascular management of cerebral arteriovenous malformations. Neurointerventionist 1999; 1: 34-40.

16. Abdulrauf SI, Malik GM, Awad IA. Spontaneous angiographic obliteration of cerebral arteriovenous malformations. Neurosurgery 1999; 44: 280-287; discussion 287-288.

17. Patel MC, Hodgson TJ, Kemeny AA, et al. Spontaneous obliteration of pial arteriovenous malformations: a review of 27 cases. AJNR Am J Neuroradiol 2001; 22: 531-536. 
18. Viñuela F, Fox AJ, Debrun G, et al. Progressive thrombosis of brain arteriovenous malformations after embolization with isobutyl 2-cyanoacrylate. AJNR Am J Neuroradiol 1983; 4: 1233-1238.

19. Bendok BR, Getch CC, Ali MJ, et al. Spontaneous thrombosis of a residual arteriovenous malformation in eloquent cortex after surgery: case report. Neurosurgery 2002; 50: 1142-1145; discussion $1145-1146$

20. Berthelsen B, Löfgren J, Svendsen P. Embolization of cerebral arteriovenous malformations with bucrylate. Experience in a first series of 29 patients. Acta Radiol 1990; 31: 13-21.
21. Arteriovenous Malformations. In: Harrigan MR, Deveikis JP, eds. Handbook of Cerebrovascular Disease and Neurointerventional Technique [Internet]. Humana Press, Totowa 2009 [cited 2016 Mar 14]. Available from: http://link.springer.com/10.1007/978-1-60327-125-127.

22. Mounayer C, Hammami N, Piotin M, et al. Nidal embolization of brain arteriovenous malformations using Onyx in 94 patients. AJNR Am J Neuroradiol 2007; 28: 518-523.

23. Spetzler RF, Martin NA, Carter LP, et al. Surgical management of large AVM's by staged embolization and operative excision. J Neurosurg 1987; 67: 17-28. 